\title{
High-Efficiency Fluorescent Blue Organic Light-Emitting Device with Balanced Carrier Transport
}

\author{
Jiun-Haw Lee, ${ }^{\mathrm{Z}}$ Yu-Hsuan Ho, Tien-Chun Lin, and Chia-Fang Wu \\ Graduate Institute of Electro-optical Engineering and Department of Electrical Engineering,
} National Taiwan University, Taipei, Taiwan

We demonstrate a blue fluorescent organic light-emitting device having a current efficiency of $19.2 \mathrm{~cd} / \mathrm{A}$ and an external quantum efficiency of $8.32 \%$ at $100 \mathrm{~cd} / \mathrm{m}^{2}$. While driving at $20 \mathrm{~mA} / \mathrm{cm}^{2}$, the device showed a current efficiency of $16.5 \mathrm{~cd} / \mathrm{A}$ with a CIE coordinate at $(0.155,0.239)$ and an operation voltage of $5.14 \mathrm{~V}$. The estimated half-decay lifetime is $15,611 \mathrm{~h}$ at an initial luminance of $1000 \mathrm{~cd} / \mathrm{m}^{2}$. The improved performance is the result of better carrier balance which is achieved by using bis $(10$ hydroxybenzo $[h]$ quinolinato)beryllium $\left(\mathrm{Bebq}_{2}\right)$ as the electron-transport layer. (C) 2007 The Electrochemical Society. [DOI: 10.1149/1.2737659] All rights reserved.

Manuscript submitted December 28, 2006; revised manuscript received March 16, 2007. Available electronically May $22,2007$.

Organic light-emitting devices (OLEDs) have attracted much attention owing to their advantages of low power consumption, high brightness, high contrast, and potentially low cost. ${ }^{1,2}$ Among the three primary stimuli, blue OLED typically exhibits lower current efficiency and shorter operation lifetime than red and green ones which has significantly hampered the development of full-color OLED. ${ }^{3,4}$ Compared to green and red devices, blue OLED has the shortest wavelength and hence the highest photon energy. Therefore, in achieving a blue phosphorescent OLED, very wide bandgap materials for both host and dopant are needed, which is rather difficult in terms of material design and synthesis. ${ }^{5}$ The high cost of heavy metal phosphorescent material is also one of the key obstacles that prevent the widespread of phosphorescent OLED. It is therefore believed that making a blue fluorescent OLED with high efficiency and long operation lifetime is one of the most important tasks for OLED development in the near future.

In our blue fluorescent OLED, we used 9,10-bis(2'-naphthyl) anthracene (ADN) and 4,4'-bis[2-(4-( $N, N$-diphenylamino)phenyl) vinyl] biphenyl (DPAVBi) as the host and dopant materials for the emitting layer (EML), respectively. A device with similar combination of the organic materials reported by Lee et al. ${ }^{6}$ showed a current efficiency of $9.7 \mathrm{~cd} / \mathrm{A}$ with $\mathrm{CIE}_{x, y}(0.16,0.32)$ and operation voltage of $5.7 \mathrm{~V}$ at $20 \mathrm{~mA} / \mathrm{cm}^{2}$. The half-decay lifetime at an initial brightness of $1000 \mathrm{~cd} / \mathrm{m}^{2}$ is $46,000 \mathrm{~h}$. Typically, the hole mobility of a hole-transport layer (HTL) material is much higher than the electron mobility of an electron-transport layer (ETL) material. Such unbalanced carrier mobility between HTL and ETL materials results in low device efficiency and shortens the operation lifetime. ${ }^{7}$ A composite-HTL (c-HTL) was used to impede the hole transport for achieving charge balance and significantly increased the current efficiency from 10.4 to $16.2 \mathrm{~cd} / \mathrm{A}$. ${ }^{8}$ However, the operation voltage is slightly increased due to the lower hole-mobility of the c-HTL. Instead of decreasing the hole mobility, we used a high electronmobility ETL, bis(10-hydroxyben-zo[h]quinolinato)beryllium $\left(\mathrm{Bebq}_{2}\right)$, to achieve carrier balance. This material exhibits an electron mobility of one order magnitude higher than that of the typically used ETL material, tris-(8-hydroxyquinoline) aluminum $\left.(\mathrm{Alq})_{3}\right){ }^{9}$ Because the charge is more balanced and the mobility value of the ETL is higher, the current efficiency increases with lower operation voltage, which, in turn, leads to lower power consumption.

\section{Experimental}

In our blue fluorescent OLEDs, we used $N, N^{\prime}$-diphenyl$N, N^{\prime}$-bis(1-naphthyl)-1, $1^{\prime}$-biphenyl-4, $4^{\prime}$-diamine (NPB) as the HTL material, DPAVBi of different concentrations doped in ADN as the EML, and $\mathrm{Bebq}_{2}$ as the ETL, followed by $1.2 \mathrm{~nm}$ thick LiF as the electron-injection layer between the ETL and $100 \mathrm{~nm}$ thick alu-

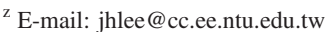

minum cathode. Table I illustrates the OLED structures. Dopant concentrations of devices 1 to 6 were $0,1,2,3,4$, and $8 \%$, respectively, for investigating the electrical and optical characteristics of DPAVBi in ADN matrix. Layer thicknesses of HTL, EML, and ETL were 40, 45, and $15 \mathrm{~nm}$, respectively. After thin-film deposition, devices were encapsulated in the $\mathrm{N}_{2}$ glove box with calcium oxide dessicant. Keithley 2400 source meter was used to determine the current-voltage (I-V) characteristics of the device, whereas Minolta CS-1000 photometer was used to measure the luminance, the spectrum, and the CIE coordinate of the device. Operation lifetime was measured while the device was driven by constant dc current with different initial luminances.

\section{Results and Discussion}

Figure 1 shows the current density-voltage (J-V) characteristics of devices 1 to 6 . At the current density of $100 \mathrm{~mA} / \mathrm{cm}^{2}$, the driving voltage changes slightly from 6.2 to $6.6 \mathrm{~V}$. Note that the dopant concentration did not affect the J-V characteristics significantly. Typically, if a dopant acts as a trap in a matrix, the operation voltage will increase with increasing dopant concentration. However, in our DPAVBi/ADN devices, the driving voltage is nearly the same; no obvious trend of voltage-shift is observed with different dopant concentrations. Hence, we attribute the minor voltage difference to the inevitable experimental errors. Compared to other OLEDs, the operation voltages of our devices are quite low. ${ }^{6}$ Such low operation voltage is the result of using high electron-mobility ETL material, $\mathrm{Bebq}_{2}$.

Figure 2 shows the dependence of the current efficiency (in terms of cd/A) and the current density. It is obvious that the current efficiency increases rapidly as the dopant concentration increases from 0 to $2 \%$ which is due to the enhanced energy transfer from the host to the dopant materials. When the dopant ratio is between 2 and $4 \%$, the current efficiency reaches a plateau with maximum value. The optimized dopant concentration is $3 \%$ (device 4) with a current efficiency of $16.5 \mathrm{~cd} / \mathrm{A}$ at $20 \mathrm{~mA} / \mathrm{cm}^{2}$ and $19.2 \mathrm{~cd} / \mathrm{A}$ at $100 \mathrm{~cd} / \mathrm{m}^{2}$. Such high current efficiency is attributed to the improved carrier balance. The improved device performance is due to the incorpora-

Table I. Layer structures of the OLED devices.

\begin{tabular}{|c|c|c|c|c|c|}
\hline Device & HTL & $\begin{array}{l}\text { EML } \\
\text { Host }\end{array}$ & Dopant $(\%)$ & ETL & $\begin{array}{c}\text { CIE } \\
\text { coordinates }\end{array}$ \\
\hline & NPB & ADN & DPAVBi & $\mathrm{Bebq}_{2}$ & \\
\hline 1 & $40 \mathrm{~nm}$ & $45 \mathrm{~nm}$ & 0 & $15 \mathrm{~nm}$ & $(0.178,0.213)$ \\
\hline 2 & & & 1 & & $(0.175,0.220)$ \\
\hline 3 & & & 2 & & $(0.159,0.238)$ \\
\hline 4 & & & 3 & & $(0.154,0.238)$ \\
\hline 5 & & & 4 & & $(0.154,0.242)$ \\
\hline 6 & & & 8 & & $(0.160,0.270)$ \\
\hline
\end{tabular}




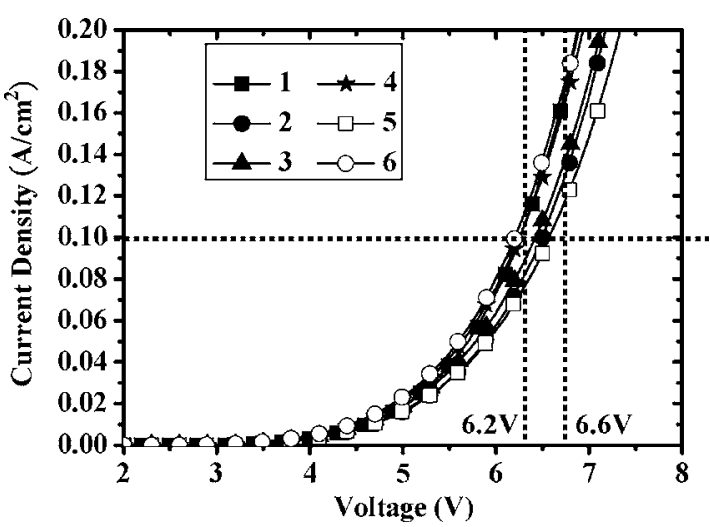

Figure 1. Current density vs voltage curves of devices 1-6.

tion of high-mobility ETL, Bebq 2 , which leads to better charge balance in the blue OLEDs because they are typically hole-limited devices. When the dopant concentration further increases to $8 \%$, the current efficiency drops (in Fig. 3) and the emission red-shifts (in Table I), which represents a typical concentration quenching effect. ${ }^{10}$ Note also that as the dopant concentration increases from $0 \%$ to $8 \%$, the $y$-value of the CIE coordinates increases, which may come from the solid-state solvation effect. ${ }^{11}$

Figure 3 shows the normalized spectra and luminance profile of our optimized blue OLED, Device $4(\mathrm{DPAVBi}=3 \%)$, at different viewing angles. Typically, the thin-film structure of OLED can be viewed as a Fabry-Perot microcavity. ${ }^{12,13}$ From Fig. 3a, when normalizing the peak at $460 \mathrm{~nm}$, we observe the decrease of the peak at $485 \mathrm{~nm}$ with increasing the viewing angles because the resonant wavelength of the microcavity is proportional to the value of the $\cos \theta$, where $\theta$ is the angle to the normal of the device that accounts for this blue shift. ${ }^{14,15}$ In addition, a small hump near $525 \mathrm{~nm}$ is also observed, which comes from the emission of $\mathrm{Bebq}_{2}$. Because ADN exhibits ambipolar carrier-transport characteristics, the holes may transport through the EML to recombine with electrons in the ETL. ${ }^{16}$ This explains why our blue OLED with higher electronmobility ETL has higher efficiency compared to the conventional blue OLEDs with $\mathrm{Alq}_{3}$ as the ETL. ${ }^{17}$ As shown in Fig. 3b, the luminance is nearly constant at different viewing angles. It is a typical Lambertian source which was predicted by the "half-space" optical model that accounts for optical interference effects of the metal cathode-reflector in a weak-microcavity OLED. ${ }^{18}$ The external quantum efficiency of the optimized device is as high as $8.32 \%$, which is close to the physical limit of the fluorescent device reported in Ref. 19.

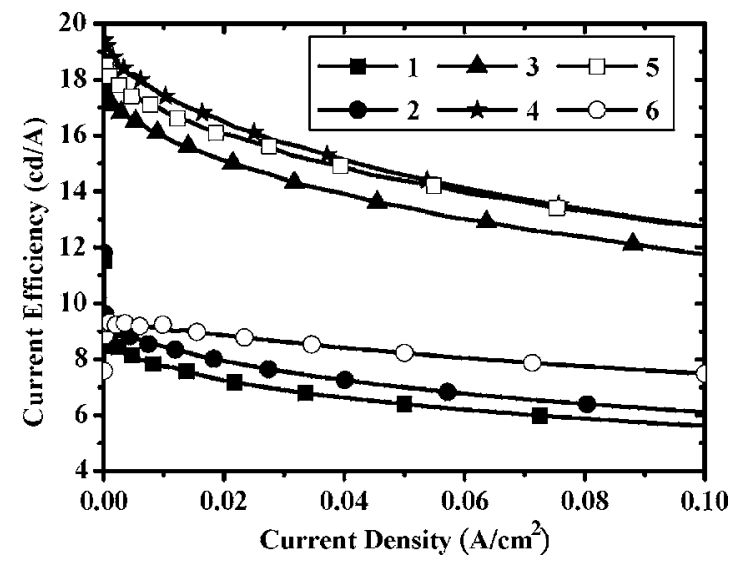

Figure 2. Luminance vs current density of devices 1-6.
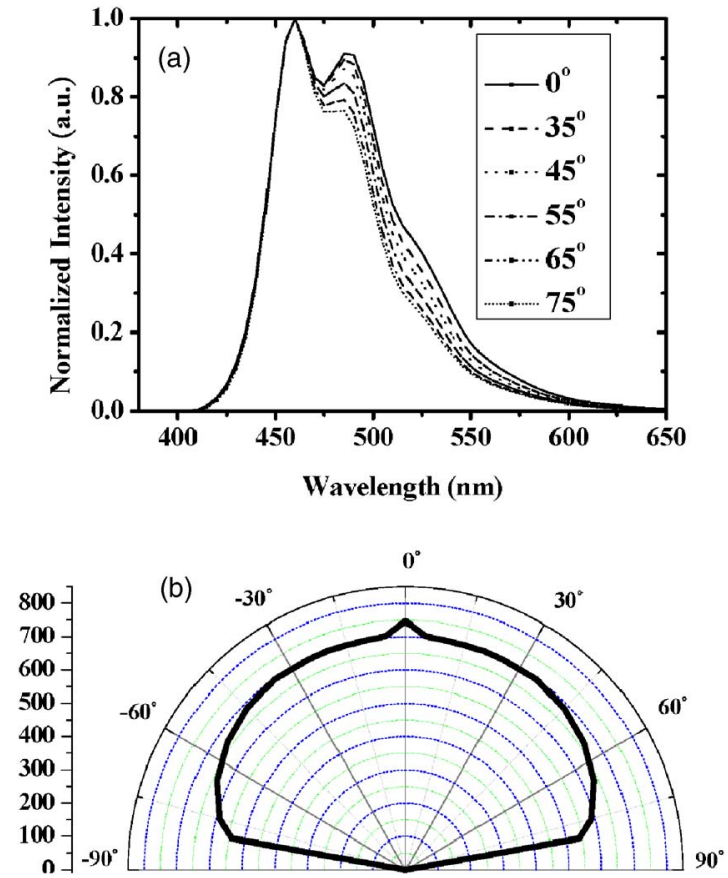

Figure 3. (Color online) (a) Spectra and (b) luminances at different view angles of device 4 .

Figure 4a shows the results of the accelerated operation lifetime tests of Device 4 with different initial luminances. The extrapolated half-decay lifetimes under the initial luminance of 5000, 7500,
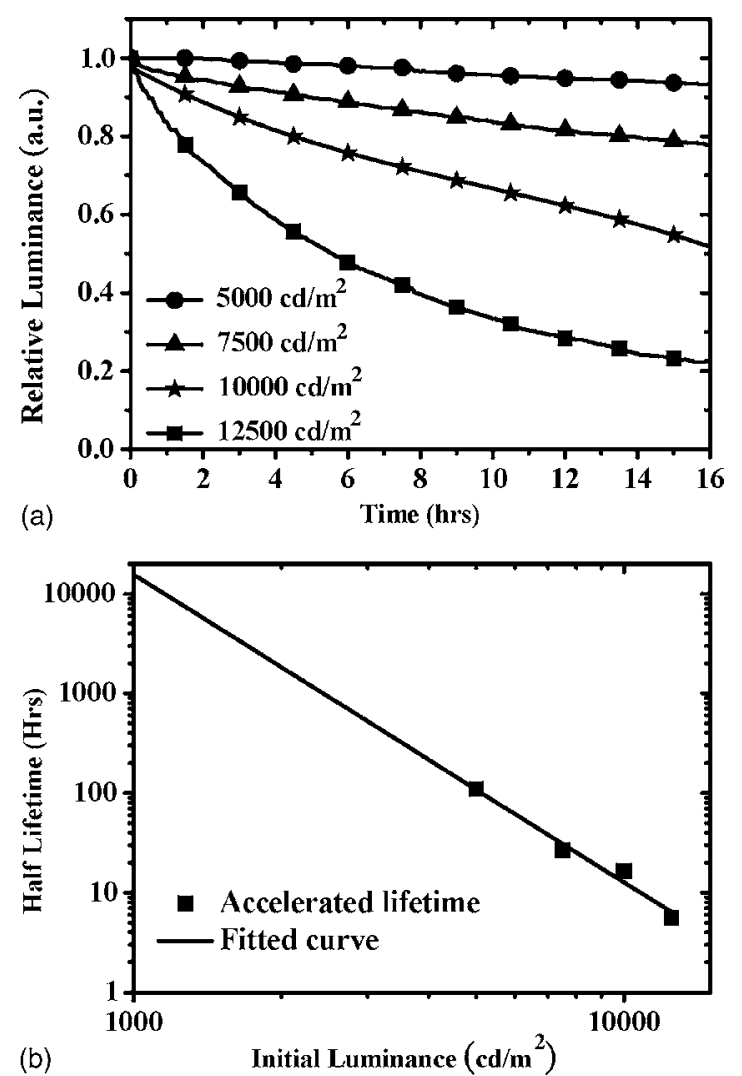

Figure 4. (a) Accelerated operation lifetime measurement and (b) halflifetime with different initial luminances of device 4 
10,000 and $12,500 \mathrm{~cd} / \mathrm{m}^{2}$ are $109.8,27.0,16.6$, and $5.6 \mathrm{~h}$, respectively. The half-decay lifetimes under different initial luminances were determined by the equation shown below as illustrated in Fig. $4 b^{20}$

$$
L^{*} t_{1 / 2}{ }^{n}=C
$$

where $n$ is the acceleration coefficient and $t_{1 / 2}$ is half-decay lifetime. The best fitting acceleration coefficient value is 3.088 . Hence, the estimated half-decay lifetime of 15611 and $1836 \mathrm{~h}$ are achieved at an initial luminance of 1000 and $2000 \mathrm{~cd} / \mathrm{m}^{2}$, respectively. This value is quite similar to that obtained in Ref. $6(2400 \mathrm{~h}$ at initial luminance of $1940 \mathrm{~cd} / \mathrm{m}^{2}$ ) due to similar organic materials used for the EML.

\section{Conclusion}

In summary, we have shown a high-efficiency and long operation lifetime blue OLED using DPAVBi doped ADN the EML and Bebq as high electron-mobility ETL. The current efficiency and EQE of the optimized device at $100 \mathrm{~cd} / \mathrm{m}^{2}$ are $19.2 \mathrm{~cd} / \mathrm{A}$ and $8.32 \%$, respectively. While driving at $20 \mathrm{~mA} / \mathrm{cm}^{2}$, the device demonstrated a current efficiency of $16.5 \mathrm{~cd} / \mathrm{A}$ with $\mathrm{CIE}_{x, y}(0.15,0.239)$ and an operation voltage of $5.14 \mathrm{~V}$. The estimated half-decay lifetime is $15,611 \mathrm{~h}$. at an initial luminance of $1000 \mathrm{~cd} / \mathrm{m}^{2}$.

\section{Acknowledgments}

This work was supported by the National Science Council, ROC, under grant no. NSC 95-2221-E-002-305 and by the Chi-Mei Optoelectronics Corp.

National Taiwan University assisted in meeting the publication costs of this article.

\section{References}

1. C. W. Tang and S. A. Vanslyke, Appl. Phys. Lett., 51, 913 (1987).

2. C. W. Tang, S. A. Vanslyke, and C. H. Chen, J. Appl. Phys., 65, 3610 (1989).

3. Q. Huang, K. Walzer, M. Pfeiffer, V. Lyssenko, G. He, and K. Leo, Appl. Phys. Lett., 88, 113515 (2006)

4. S. Chew, P. Wang, Z. Hong, S. Tao, J. Tang, C. S. Lee, N. B. Wong, H. Kwong, and S. T. Lee, Appl. Phys. Lett., 88, 183504 (2006)

5. R. J. Holmes, S. R. Forrest, T. Sajoto, A. Tamayo, P. I. Djurovich, M. E. Thompson, J. Brooks, Y. J. Tung, B. W. D'Andrade, M. S. Weaver, R. C. Kwong, and J. J. Brown, Appl. Phys. Lett., 87, 243507 (2005).

6. M. T. Lee, H. H. Chen, C. H. Liao, C. H. Tsai, and C. H. Chen, Appl. Phys. Lett., 85, 3301 (2004).

7. J. H. Lee, J. J. Huang, C. C. Liao, P. J. Hu, and Y. Chang, Chem. Phys. Lett., 402, 335 (2005).

8. C. H. Liao, M. T. Lee, C. H. Tsai, and C. H. Chen, Appl. Phys. Lett., 86, 203507 (2005).

9. J. H. Lee, C. I Wu, S. W. Liu, C. A. Huang, and Y. Chang, Appl. Phys. Lett., 86, 103506 (2005).

10. S. A. Van Slyke, C. H. Chen, and C. W. Tang, Appl. Phys. Lett., 69, 2160 (1996).

11. M. A. Baldo, Z. G. Soos, and S. R. Forrest, Chem. Phys. Lett., 347, 297 (2001).

12. J. H. Lee, K. Y. Chen, C. C. Hsiao, H. C. Chen, C. H. Chang, Y. W. Kiang, and C. C. Yang, J. Disp. Technol., 2, 130 (2006).

13. H. C. Chen, J. H. Lee, C. C. Shiau, C. C. Yang, and Y. W. Kiang, J. Lightwave Technol., 24, 2450 (2006).

14. N. Takada, T. Tsutsui, and S. Saito, Appl. Phys. Lett., 63, 2032 (1993).

15. A. Dodabalapur, L. J. Rothberg, T. M. Miller, and E. W. Kwock, Appl. Phys. Lett. 64, 2486 (1994).

16. S. C. Tse, S. K. So, M. Y. Yeung, C. F. Lo, S. W. Wen, and C. H. Chen, Chem. Phys. Lett., 422, 354 (2006).

17. S. W. Culligan, A. C. A. Chen, J. U. Wallace, K. P. Klubek, C. W. Tang, and S. H. Chen, Adv. Funct. Mater., 16, 1481 (2006).

18. J. S. Kim, P. K. H. Ho, N. C. Greenham, and R. H. Friend, J. Appl. Phys., 88, 1073 J. S. Kim,

19. Y. R. Do, Y. C. Kim, Y. W. Song, and Y. H. Lee, J. Appl. Phys., 96, 7629 (2004)

20. C. Féry, B. Racine, D. Vaufrey, H. Doyeux, and S. Cinà, Appl. Phys. Lett., 87, 213502 (2005). 